\title{
Desvendando o senso do limite de familiares que convivem com pessoa dependente de cuidados físicos ${ }^{1}$
}

\section{Unveiling the sense of limit of relatives living with a member in need of physical care}

\author{
Desentrañando el sentido del límite de familiares que conviven con persona \\ dependiente de cuidados físicos
}

\author{
Maria das Neves Decesaro', Clarice Aparecida Ferraz"
}

\author{
${ }^{1}$ Extraído da Tese "Dinâmica das relações familiares: compreendendo o convívio com familiar dependente de cuidados físicos". Defendida em \\ 2007. Financiada pelo CNPq. \\ I Enfermeira. Doutora em Enfermagem pela Escola de Enfermagem de Ribeirão Preto/Universidade de São Paulo (EERP/USP). \\ Professora da Universidade Estadual de Maringá. Membro do Núcleo de Ensino, Pesquisa, Assistência e Apoio à Família (NEPAAF). \\ Email: mndecesaro@uem.br. \\ "Enfermeira. Prof ${ }^{\mathrm{a}}$ Associado da EERP/USP. Membro efetivo do Centro colaborador para o desenvolvimento da pesquisa na enfermagem. \\ Email: erraz@eerp.usp.br.
}

\section{RESUMO}

A situação de doença e dependência de uma pessoa afeta a vida familiar, provocando alterações nos papéis e nas responsabilidades, imprimindo mudanças na rotina pessoal e nas relações do grupo. Este estudo tem por objetivo apresentar características do senso do limite, com seus aspectos de trágico e teatralidade, que participam ou estão presentes na dinâmica das relações cotidianas de familiares que passaram a conviver com um de seus membros dependente de cuidados físicos. Trabalhamos com a abordagem qualitativa de pesquisa segundo o referencial teórico-metodológico de Michel Maffesoli, o qual utiliza como alavanca metodológica o formismo. Foram coletados dados no domicílio de quatro famílias, no período de julho a dezembro de 2004, utilizando as técnicas de entrevista e grupo focal. Os resultados revelaram que o senso de limite, estimulado pela presença da doença no viver cotidiano, promove a manifestação de sentimentos diversificados e mudanças nas rotinas e hábitos do dia-a-dia. Por outro lado a prática do cuidado, exigida pelo trágico da doença, propicia a união familiar. Todas as ações efetuadas para defrontar as imposições físicas, emocionais e sociais que emergem do trágico, e exibem a teatralidade vivida cotidianamente, declaram a vontade de mudança e o enfrentamento das imposições, buscando o hedonismo.

Descritores: Família; Relações familiares; Processo saúde-doença; Enfermagem.

\section{ABSTRACT}

Illness and a person's dependence affect the life of a family, provoking alterations in roles and responsibilities, producing changes in the personal routine and in the relationship of the group. This study has the purpose to present characteristics of the sense of limit, with its theatrical and tragic aspects, which participate or are present in the dynamics of daily relationships of relatives that live with one of their members depending on physical care. We worked with a qualitative approach research according to Michel Maffesoli's theoretical-methodological referential, which uses the formism as a methodological lever. Data was collected in the four families' homes, from July to December of 2004, using the interview technique and focal group. The results revealed that the sense of limit, stimulated by the presence of an illness in a daily life, promotes the manifestation of diversified feelings and changes in the routine and daily habits. On the other hand, the caring demanded by the tragicalness of the illness propitiates a family union. All the actions taken to confront the physical, emotional and social impositions that emerge from the tragicalness, and exhibit the theatricality lived daily, show the desire for changes and the resistance to the impositions, searching for the hedonism.

Descriptors: Family; Family relations; Health-disease process; Nursing.

\section{RESUMEN}

La situación de enfermedad y dependencia de una persona afecta la vida familiar provocando alteraciones en los papeles y en las responsabilidades, reproduciendo cambios en la rutina personal y en las relaciones del grupo. Este estudio tuvo por objetivo presentar características del sentido de límite, con sus aspectos de trágico y teatralidad, que participan o están presentes en la dinámica de las relaciones cotidianas de familiares que empezaran a convivir con un de sus miembros dependiente de cuidados físicos. Trabajamos con el abordaje cualitativo de pesquisa, según el referencial teórico metodológico de Michel Maffesoli, el cual utiliza como palanca metodológica el formismo. Fueron colectados datos en el domicilio de cuatro familias, en el período de julio a diciembre 2004, utilizando las técnicas de entrevista y grupo focal. Los resultados revelaron que el sentido de límite, estimulado por la presencia de enfermedad en el vivir cotidiano, promueve la manifestación de sentimientos diversificados y cambios en las rutinas y hábitos del día a día. Por otro lado, la práctica del cuidado exigida por el trágico de la enfermedad, propicia la unión familiar. Todas las acciones efectuadas para confrontar las imposiciones físicas, emocionales y sociales, que emergen del trágico y exhiben la teatralidad vivida cotidianamente declaran la voluntad de cambio y el enfrentamiento de las imposiciones, buscando el hedonismo.

Descriptores: Familia; Relaciones familiares; Proceso salud-enfermedad; Enfermería. 


\section{NTRODUÇÃO}

Com todas as transformações ao longo da história, a família se faz presente socialmente de forma peculiar, caracterizada intensamente pela dinâmica das relações, perseverando como condição para a humanização e a socialização e servindo de alicerce para o desenvolvimento e realização das pessoas $^{(1)}$.

Diversos trabalhos apresentam a situação de doença e dependência de um familiar afetando os mais variados aspectos da vida do grupo, provocando alterações nos papéis familiares e nas responsabilidades e imprimindo mudanças na rotina pessoal e nas relações ${ }^{(2)}$.

Neste sentido, observamos o emergir de um contexto de complexidade e singularidade diante do impacto da situação de doença. O cotidiano e as relações familiares sofrem mudanças quando há um familiar dependente de cuidados físicos, em virtude das alterações que ocorrem nas interações e nos padrões pré-estabelecidos de organização do grupo, constituindo-se em uma situação delicada para as pessoas, em que é exigida uma redefinição de papéis na família ${ }^{(3)}$. Percebemos que as manifestações de aceitação ou de rejeição apresentam-se então de diversas maneiras, dependendo das crenças, valores e características individuais e culturais de cada família e de seus componentes.

Destarte, podemos pensar a doença com dependência como sendo o "limite", e esse entendido como a determinação, a definição, a delimitação do movimento de viver e "com-viver", apontando que o social está cercado de coerção e de opressão. O senso do limite porta a compreensão de que a vida é limitada, a morte está ali, e não temos solução para essa evolução, mas temos proposições para nos mantermos resistindo diante das imposições ${ }^{(4)}$.

$\mathrm{Na}$ epistemologia maffesoliana o senso do limite é uma categoria que possibilita a visualização de duas subcategorias importantes para a nossa pesquisa, que são o trágico e a teatralização ${ }^{(4-5)}$.

O trágico apresenta-se como característica natural de toda estruturação social, do viver em sociedade, da relação do homem com a natureza. Ao introduzir a noção de trágico, o autor expressa que nessa contingência não há evolução. Pode-se entender, então, que esta é a expressão máxima do querer-viver de toda existência individual e coletiva. Esse querer-viver diante do trágico da vida pode se apresentar de forma latente, exacerbada ou perversa, mas haverá manifestação de revolta contra todas as imposições mortíferas da vida; assim, o trágico é um grande guerreiro natural presente no viver cotidiano ${ }^{(5)}$.

A teatralidade é outro elemento significativo da pós-modernidade, que difunde-se na vida cotidiana, na política, na ideologia, na religião, apresentando-se com força e expressão( ${ }^{(5)}$.
O teatral se manifesta fortemente nas relações familiares ou outras formas de grupo restrito, porquanto se entende que todas as relações compostas pelos aspectos da harmonia e do conflito dependem de encenação, e sendo assim é muito difícil a vida social realizar-se apoiada sobre a autenticidade. Para melhor esclarecer, 0 autor parafraseia Duvignaud: "a essência da vida coletiva e da existência individual é teatral"(4).

Pensando na singularidade do ambiente familiar com a presença da doença, este trabalho tem por objetivo apresentar elementos apreendidos da categoria maffesoliana senso do limite, com seus aspectos de trágico e teatralidade, que participam ou estão presentes na dinâmica das relações cotidianas de familiares, que, inesperadamente, passam a conviver com um familiar adulto que se tornou dependente de cuidados físicos.

\section{CAMI NHO METODOLÓGI CO}

O suporte metodológico escolhido para este pesquisa foi a abordagem qualitativa de pesquisa embasado na sociologia do cotidiano de Michel Maffesoli, em virtude desta permitir apreender a realidade concreta do objeto de investigação, tornando-se apropriada para o estudo da estruturação social das famílias que, repentinamente, passaram a conviver com familiar dependente de cuidados $^{(4)}$.

Sustentados na epistemologia maffesoliana, elegemos para este estudo o formismo como recurso de investigação que se ajusta à necessidade metodológica de dar contornos aos fenômenos societais, visto que este se satisfaz em delinear ou desenhar o fenômeno social sem buscar uma finalidade exata dos mínimos atos da vida cotidiana $^{(4)}$.

O neologismo formismo é empregado para distinguir do termo formalismo utilizado por outros autores, e não mais permitir os disparates sugeridos pela idéia de forma. O formismo aceita as aparências enquanto tais; já o formalismo esforça-se em dar sentido a tudo o que observa(6).

Os pressupostos formistas asseguram que para ser científico não é necessário diminuir e extinguir o que se julga não ser essencial; tudo tem valor, tudo é colocado em relevo ${ }^{(6)}$.

Deste modo, para alcançar o objetivo proposto para este estudo, o nosso olhar esteve dirigido ao entorno do estar-junto-coletivo da família, enfocando a pessoa com dependência física e os membros familiares, explorando a convivialidade, a dinâmica das relações interpessoais no cotidiano, a partir da família e da epistemologia maffesoliana.

Elegemos alguns critérios para a entrada das famílias na pesquisa: iniciar o convívio no domicílio no pós-alta hospitalar, devendo o familiar ter-se tornado dependente físico há mais de um mês e 
menos de três meses; ser a primeira experiência de convívio com familiar dependente de cuidados físicos; a família contar com quatro ou mais membros, fator importante e necessário para a aplicação das técnicas de coleta de dados propostas.

As famílias que atendiam aos critérios de inclusão para o estudo eram recomendadas pelos profissionais das equipes do Programa Saúde da Família das 24 Unidades Básicas de Saúde do município de Maringá-PR. Foram coletados dados junto a quatro famílias de pessoas adultas dependentes de cuidados físicos, em conseqüência de doença ou trauma que desencadeou a seqüela; em todas as famílias o dependente era um progenitor.

A coleta de dados aconteceu no período de julho a dezembro de 2004, sendo realizada no domicílio. Empregamos como técnicas de coleta de dados a entrevista individual aberta (EI), com o dependente (Dep.) e com os membros familiares; foram efetuados quatro grupos focais (Gf I - Gf II - Gf III Gf IV) em cada família, sem a presença do dependente físico. Em uma das famílias não foi possível desenvolver a entrevista com o doente por este estar afásico.

Foram considerados os princípios éticos preconizados pela Resolução no 196/96-MS, para o desenvolvimento da pesquisa. O projeto foi aprovado pelo Comitê Permanente de Ética em Pesquisa Envolvendo Seres Humanos da Universidade Estadual de Maringá - Parecer no 152/2004. Todos os participantes assinaram o termo de consentimento livre e esclarecido.

As famílias estudadas tinham em comum apenas a presença de uma pessoa adulta dependente de cuidados físicos, no mais, cada uma tinha a sua peculiaridade e singularidade, as quais foram levadas em consideração em todo processo do desenvolvimento da pesquisa.

As próprias famílias determinaram sua identificação e a denominação de cada membro familiar, de tal modo que serão referidas no estudo como: Família Afeto (F.Afeto), Família Cores (F.Cores), Família Pássaro (F.Pássaro) e Família Flores (F. Flores).

\section{RESULTADOS E DISCUSSÃO}

\section{Submergindo no viver das famílias para desvendar o senso do limite}

O senso do limite apresenta características intrínsecas ao viver cotidiano, ou seja, o senso do limite na epistemologia maffesoliana quer nos dizer que não há como interromper tantas coisas e acontecimentos da vida, inexistindo meios de impedir que sucedam em seu transcurso natural ${ }^{(4-5)}$.

Sendo assim, para assegurar o viver do dia-a-dia não podemos negar as pequenas mortes presentes na trama da vida cotidiana. Neste sentido o foco de análise privilegia a articulação da noção teórica do senso do limite - com seus aspectos de trágico e teatralidade - aos dados empíricos da pesquisa.

$\underline{\text { Invadindo o fervilhar do cotidiano para apreender } 0}$ trágico vivido

A presença inesperada da doença no contexto familiar configura-se por si só como uma vivência trágica, o que nos instiga a mergulhar nesse conjunto social para compreender essa situacionalidade.

Nesta subcategoria que trata do trágico no viver cotidiano familiar procuramos visualizar, nas falas, as pequenas perdas que fazem parte do conviver das famílias. Assim, fomos percebendo manifestações de sentimentos diversificados e denúncias de que as frustrações, angústias, etc., entendidas como pequenas mortes, podem também ser absorvidas na rotina de todos os dias, passando a integrar o viver: [...] ontem mesmo veio uma mulher e falou assim: 'Margarida, pára de xingar e respeita as suas meninas e as suas meninas também respeita você'. Mas quando é amanhã ela vai e xinga de novo! Ela fala que vai parar e não pára [silêncio] [...] (Papoula/Gf IV).

No seio familiar ocorrem manifestações de sentimentos que são peculiares e se exibem de acordo com as interferências no viver e conviver do dia-a-dia. Para um dos familiares, que se tornou cuidador, afastar-se do trabalho profissional foi a condição, o que representou um fenômeno trágico e de sofrimento na sua vida, desencadeando sentimentos distintos:

[...] Para mim (esposa) no começo foi muito difícil, tive que parar de trabalhar e é tudo que gosto de fazer; e quanto aos meus sentimentos é sofrido, por ver uma pessoa dependente de tudo, por mais que a recuperação dele (esposo e dependente) tem sido muito boa, mas às vezes quando paro para pensar fico muito triste, mas olho para ele e ainda agradeço a Deus por tudo [...] (Mãe Arara/F. Pássaro).

O conviver com a doença pode promover o desânimo dos familiares e também do dependente físico, como registrado a seguir:

Está muito difícil [...], não muda nada de jeito nenhum, cada dia que eu (esposa) chego é a mesma coisa, nada muda meu Deus do céu [...] (Amor/Gf II).

[...] Foi muito difícil pra mim, teve hora de chegar no ponto de até desanimar mesmo, desanimar, e não tentar recuperar totalmente, foi uma fase difícil [...]. Eu sentia assim muito frágil, muito dependente, me sentia muito incapacitado, muito inútil, muito inútil ficar dependendo deles [...] (Ararão/Dep. F. Pássaro).

No trágico é possível encontrar uma pluralidade de sentimentos e de situações que refletem, ao mesmo tempo, o ríspido e o suave, a rudeza e a doçura, que se apresentam em conjunto na busca de 
um ordenamento da vida social. Os sentimentos de impotência, de incapacidade das pessoas diante dos obstáculos que se exibem com a presença da dependência física nas famílias são intensos, e a nãoaceitação da doença, revelada por todos os dependentes, incita o surgimento do sentimento de inutilidade $^{(4)}$.

Estudos exibem que as emoções que afloram dos cuidadores, e dos próprios dependentes, podem apresentar-se de forma antagônica, refletindo o desgaste da situação causado pela presença da doença. Assinala que ao doente expor o sentimento de inutilidade, por necessitar de outras pessoas para a realização das atividades básicas cotidianas, está colocando em evidencia a fragilidade do ser humano. Encontramos, também, esta fragilidade revelada na compreensão dos próprios profissionais de enfermagem, os quais entendem que a limitação dos doentes, sustenta uma concepção negativa da dependência, e que a mesma é motivo de desesperança para a pessoa ${ }^{(7-9)}$.

Nesta acepção, a integração do trágico ao viver do dia-a-dia é possível se houver resgate do estético, no seu sentido de sensível, de emoção, de comunhão, presente nas insignificâncias do viver cotidiano e da coletividade. Expressar a integração do trágico representado pelas mortes vividas cotidianamente constitui-se em dizer sim a vida, mesmo com a diversidade de elementos e sentimentos que emergem nestes momentos. Mas, a integração do trágico é, principalmente, a compreensão de que tudo se esgota no sensível, que o importante são as coisas que se deixam viver pelos sentidos e que participam da socialidade ${ }^{(5)}$.

O trágico da doença, em uma das famílias estudadas, acentua-se quando o filho não assume nenhuma responsabilidade por cuidar do pai, e ao mesmo tempo não aceita a maneira como os outros membros familiares estão conduzindo este cuidado, exigindo que o façam de forma diferente:

[...] falei pro Determinação, 'você só cobra, cobra, cobra [com veemência] e exige, e todas as coisas que você está exigindo..., você acha que alguém da sua família tem culpa de seu pai estar como ele está? Eles não têm culpa. O seu pai está na situação que está porque ele mesmo procurou isso. [...] o culpado dele é ele mesmo e não tem ninguém culpado' [...] (Dedicação/Gf III).

Durante as visitas domiciliares observamos que o dependente era muito bem cuidado, recebia atenção e dedicação da família, mas o filho que reclamava (Determinação) não participava do cuidado, e somente com o tempo ele reintegrou-se à família. As divergências que algumas vezes ocorre nas condutas de cuidado ao dependente, aonde um dos familiares queira impor sua forma de cuidar, pode causar angústia e atritos nas relações entre os $\operatorname{membros}^{(7)}$. Esses conflitos familiares devido a não- colaboração no cuidado pode advir de várias fontes, dentre elas a presença de mágoas e rancores com o doente, os trabalhos externos e/ou deveres com o cônjuge e filhos(3).

Com a presença do trágico no contexto familiar, diversos aspectos sofrem alteração, dentre eles evidenciamos o econômico e às atividades sociais. Sabemos historicamente que mudanças nestes fatores interferem nos vínculos pessoais, e isso se manifesta claramente nas falas dos familiares:

[...] Pra mim (esposo Crisântemo) mudou muito, pois quando tem que levar para o médico, já não posso trabalhar, já perdi serviço bom porque não posso deixar ela assim. Tem que fazer isso, não posso deixar ela só. Então deixo de aceitar trabalhos de pedreiro para ajudar ela (Crisântemo (EI)/F. Flores).

A doença pode impedir ou prejudicar o desempenho no trabalho dos membros, responsáveis pela organização e sustento familiar. Os relatos nos permitem dizer que os gastos com materiais, alimentação, cuidados, etc. de uma pessoa acamada realmente se elevam e muitas vezes extrapolam as condições econômicas da família. Sendo assim, o peso das despesas inesperadas com a doença pode desestruturar a organização econômica da família. Além disso, se percebeu, pela observação, que o prejuízo financeiro também pode estremecer as relações familiares.

Os relatos também exibem que o trágico vivenciado pelas famílias tem abalado o ordenamento da vida:

[...] Faltei muita aula. Agora não adianta mais, perdi o boletim, [...] perdi a recuperação, agora é tarde. Perdi os meus colegas também, [...] eu não tenho mais contato com ninguém mais, não tem telefone pra ligar, não tem mais nada. Minha prima mesmo estudava lá, perdi o contato, foi péssimo [...] (Violeta (El)/F. Flores).

A família enquanto cuidadora, nas situações de dependência física, sofre mudanças nos mais variados aspectos, sendo obrigados a mudar suas atividades diárias para cuidar do doente no ambiente familiar, ocorrendo abandono das atividades domésticas, do emprego, e ainda dos estudos e do lazer.

Corroborando nossos achados temos estudos que apresenta a doença crônica, exemplo o acidente vascular cerebral e o Alzheimer, como fonte geradora de sobrecarga física, emocional e financeira aos familiares, exigindo do núcleo uma adaptação, pois esta não raro se defronta com mudanças permanentes, em que as atividades de cuidado ao dependente podem permanecer por um período considerável de tempo ${ }^{(10-11)}$.

O trágico da doença mostra-se de forma dinâmica, apresentando-se como um fator importante para a reestruturação do viver em família. Isto se declara quando membros familiares referem 
que, com o inesperado da doença, a família pensou que era o fim de tudo, e na realidade, o trágico veio para começar uma nova forma de viver, um viver com afetividade, com aproximação entre todos os membros:

“[...] A família (irmãos e pais da dependente) mudou muito [...], a família está bem mais unida [...], era o tempo todo brigando por dinheiro, o acidente acho que contribuiu pra juntar mais a família mesmo [...]" (Vermelho/Gf I).

"Tudo o que aconteceu não foi um desastre, um retrocesso, mas um caminho árduo de correção necessária para a edificação do lar [...]" (Arara (EI)/F. Pássaro).

Declara-se nos relatos que há o reconhecimento do momento difícil, contudo as pessoas conseguem ver além do fenômeno doença: percebem nas entrelinhas do sofrimento a vida, e procuram aproveitar estes sinais de luz e vitalidade de acordo com o que lhes é oferecido.

As distintas maneiras de estar-junto, em que se destaca a cultura dos sentimentos, da afetividade, do emocional, no lugar do puro racional, tornam possível fazer do trágico uma força que consegue agir com domínio sobre o que se apresenta no cotidiano(12).

O trágico pode apresentar-se como um sinal de alerta para a vivência de um presente alternativo, mesmo com imposições. Assim, perceber a doença como oportunidade de viver o presente é possível quando se toma consciência de que, embora a vida seja limitada, há uma proposição para o viver, como desvelam as falas:

[...] eu vejo que foi uma nova chance de fazer certo, de fazer as coisas melhor e de aproveitar o máximo. Que a vida é curta, a vida é rápida, nós somos frágeis, nós vamos acabando, o processo de determinação da vida..., então a gente tem que ir usando essa sabedoria de aproveitar o máximo [...] (Arara/Gf I).

Este relato apresenta, com profundidade, como o trágico também pode propiciar fortalecimento às pessoas da família. A doença pode permitir o crescimento pessoal, o reconhecimento da possibilidade de aproveitar a vida de outra forma, mais aberta, leve e afetiva.

O enfrentamento do trágico na vivência do diaa-dia, na visão maffesoliana, retrata que, quando é compreendida na perspectiva do heterogêneo com a inclusão do contraditorial, essa vivência permite a aceitação das fatalidades e a convivência com o cuidar e o não-cuidar, o bem e o mal, o objetivo e o subjetivo. Desta forma, as factcidades são aceitas como elas realmente se apresentam, sem postergar a dificuldade e sem esperar por uma ação definitiva e perfeita. Simplesmente se vive, com responsabilidade, mas sem se inquietar com os resultados.

Os aspectos que foram reunidos na composição desta subcategoria são relativos às mortes do dia-adia. Estas são assumidas e afrontadas, mas também são negadas; contudo a obrigatoriedade do presenteísmo leva à necessidade de viver as imposições mortíferas.

Neste sentido, o enfrentamento do trágico com o que a vida lhe oferece para viver é possível também para o dependente físico. Em uma das falas a dependente refere que inicialmente solicitava muita ajuda para ir ao banheiro à noite, o que a fazia sentir-se incômoda para os familiares; então ela procurou reeducar seu organismo para não precisar ir tanto ao banheiro.

Assim, no impacto de eventos inesperados, como mortes, desemprego, doenças, divórcios, etc., os quais desencadeiam situações críticas, cada sujeito e cada família encontram de modo singular, individual, suas maneiras de enfrentamento; porém, mesmo agindo de forma parecida ou com as mesmas estratégias, cada uma irá obter resultados diferentes, sendo que a superação da crise depende da flexibilidade com que ocorrem as interações familiares ${ }^{(13)}$.

Só na harmonia da tensão, ou seja, somente de acordo com o viver social que se faz na diferença é que se determina e se mantém o existir ${ }^{(14) .}$ Nesta compreensão entendemos que a doença propicia a exposição de tensões latentes, levando as pessoas a se despertarem para novos caminhos no viver.

Nos relatos é possível apreender aspectos que identificam certos acontecimentos do destino, impostos ao existir das pessoas e da família, os quais reconhecem a quase-obrigatoriedade de viver 0 árduo, o trágico, estas evidências se exibem na fala a seguir:

[...] O Vermelho tinha dia - coitado - que não conseguia levantar da cama de sono, porque era a noite inteira, vai pro banheiro, vai [...] assim à noite, o tempo todo, a gente corria muito. No outro dia ele estava cansado, eu também [...] (Branca/Gf I).

Esta declaração afirma com que intensidade a família, neste caso o filho, precisa assumir o cuidado com o dependente físico, demonstrando quanto isso é penoso. Outros relatos de dependentes físicos também manifestam a contingência do viver trágico, e declaram quão horrível é depender de outros, coisa que ninguém quer.

Neste contexto de cuidador e dependente, encontramos em estudos que, geralmente, os cuidadores percebem a responsabilidade do cuidado como um dever moral, instituído por aspectos psicosociais advindos das relações pessoais e familiares que se constituíram no viver cotidiano ${ }^{(7)}$.

Enfrentar com coragem o destino é partilhar da cenestesia que permite o desenvolvimento e a perduração do grupo familiar. A cenestesia pode ser compreendida como a junção de todos os elementos, é o todo se formando a partir da diversidade, da 
disparidade e até mesmo da contraditoriedade ${ }^{(15)}$.

Configura-se, ainda, o ensejo de como o trágico pode interferir e influenciar impositivamente os comportamentos e as condutas dos membros do conjunto familiar:

[...] Um inferno que a gente está! [...], pra mim está sendo o fim.[...] A gente vê que está difícil mesmo, nada dá certo, cuida, cuida, todo o mundo,[...] está sempre cuidando; só que a gente pensa: será que vai ficar sempre nessa aqui, lavando, limpando, e será que ele vai melhorar? De certa forma isto está interferindo muito na nossa vida. $\mathrm{Na}$ minha vida assim muito [com intensidade] [...] (Carinho/Gf I).

Este relato declara a intensidade com que a doença tem intervindo na vida dos membros familiares. Outros relatos exprimem que a pressão presente neste conviver tem sido tão intensa que tem possibilitado a manifestação de quadros depressivos em alguns familiares.

Entender a doença dentro do trágico é mostrar a intensidade do viver; é querer enfrentar com força e garra as imposições e dizer sim à vida, apreciando e vivenciando as pequenas mortes; é querer participar da construção das redes que compõem a socialidade.

A vida cotidiana é o lugar por excelência do trágico, onde a experiência de viver o trágico sustenta a existência das imperfeições e das vicissitudes. Para o autor, o trágico que se apresenta no instante constitui-se de paixões, pensamentos e criações que se esgotam no ato mesmo e se atualizam de forma ininterrupta, expressando as múltiplas possibilidades do fenômeno( ${ }^{(16)}$.

\section{Percorrendo os ritos na teatralização cotidiana}

O trágico sustenta-se pelo rito, que faz uso do tempo-espaço para mostrar os elementos insignificantes e anódinos da vida cotidiana, os quais se manifestam pela teatralização(4-5)

Ao falarmos de teatralização estaremos abordando o jogo da aparência que se efetua no viver individual e social, por meio do rito. A teatralização permite a apresentação de aspectos que determinam as relações com o outro.

A teatralidade é a expressão de todos os atos $\operatorname{cotidianos}^{(4)}$. Desta forma, é possível observar nos relatos a presença da teatralidade, que vai se apresentando na repetitividade do dia-a-dia, conformando características de relações familiares.

Traços peculiares de uma relação foram revelados na rotina diária de um neto passar pelo quarto do avô dependente físico para que este pudesse vê-lo ao sair para a escola; assim, sem pronunciar uma palavra, despertou uma inquietação na mãe, dando uma resposta profunda:

[...] não preciso falar nada pro avô, ele me vê, ele já sabe que eu estou indo para a escolinha (Ingenuidade Gf III/F. Afeto).

Consideramos que a maneira silenciosa de transmitir os sentimentos manifesta com intensidade uma relação de afeto, carinho e respeito. Torna-se importante entender nas entrelinhas a grandiosidade deste estar-junto.

A repetição de gestos anódinos que se realizam no decorrer do dia determina uma ambiência específica de um lugar, sendo que eles permitem a comunicação social. Esta comunicação pode ser nãoverbal, feita de rituais não pensados, gestos, tipos de comportamento que determinam sentimentos de pertença, criando religações no conjunto social ${ }^{(5)}$.

O teatral também é um importante revelador das banalidades do viver, das insignificâncias, das coisas e fatos considerados anódinos que despontam dos momentos simples e dos ritos diários, os quais se constituem como elementos organizadores das relações familiares:

[...] A gente (família) tinha esquecido como fazia certas coisas, então eu acho muito bom, acho que a vida não acabou; eu acho que agora sim é que começa, agora sim a gente valoriza cada minuto, cada segundo, cada almoço, jantar na mesa, cada sei lá..., cada momento que a gente assiste TV junto, copo de água que a gente dá, remédio que a gente dá pra ele, a gente valoriza cada detalhe, [...] (Arara/Gf I).

A teatralização é inerente ao viver social, manifestando-se pela pluralidade, heterogeneidade e contraditorial que se apresentam nas idéias e nos comportamentos das pessoas ${ }^{(6)}$.

Queremos reforçar que o contraditorial busca demonstrar que os diversos elementos contraditórios podem ter coerência, mantendo suas especificidades e oposições. A noção de contraditorial recupera a idéia de paradoxal, no sentido de viver as dificuldades dos contrários de forma equilibrada ${ }^{(17)}$.

Evidenciamos que nos rituais do cuidado a atenção para com o dependente constitui-se em importante elemento estruturante das relações familiares:

[...] parece que ele está mais forte, ele está se movendo, acho que ele está com vontade de voltar ao normal. Isso anima a gente também. Porque tem algumas coisas que ele não fazia antes, quando a gente fala assim 'pai levanta a b.', pra mim trocar ele, ele pega e levanta, assim levanta tudo; aí às vezes a gente vem lá, pega uma blusa pra ele, e tem que virar assim a cabeça pra gente colocar, ele ergue a mão pra pôr dentro o braço também, já mexe a cabeça ... (Ternura/Gf IV).

Esta fala e outras que se manifestaram nas entrevistas apresentam-se como se fossem traços de uma encenação teatral do viver cotidiano. Estes sinais podem aparentemente não ter valor para quem não está vivenciando a doença, mas para quem pertence ao contexto, estas insignificâncias compõem e firmam a potência para manter as relações e o viver do dia-a-dia. É possível perceber neste teatral 
que há um movimento de aproximação e distanciamento, porém é justamente este jogo de aparências que apresenta o concreto do viver e da estruturação das relações familiares.

Percebemos que há inúmeras manifestações do rito que se perpetuam no viver cotidiano, as quais estruturam e cimentam as relações familiares. As famílias buscaram, na divisão das tarefas conforme a disponibilidade de tempo de cada membro, atender às necessidades do dependente segundo um ritual. $\mathrm{O}$ mais importante é que eles perceberam nestas condutas uma forma de união familiar.

As múltiplas atividades que se desenvolvem no dia-a-dia, as rotinas, as regras, os rituais, os segredos, tornam-se meios de interação e proteção dos familiares, assegurando a continuidade de geração a geração, mesmo com as alterações externas $^{(18)}$.

Nós podemos dizer que há nisto um teatral em ato, exibindo a expressão de pequenos ritos, que a um olhar superficial parecem insignificantes, porém, se observados de forma a valorizar sua participação no conjunto podem ser percebidos como produtores e estruturadores do fenômeno e das relações.

Apreender a teatralidade cotidiana é compreender a lição da ritualização, onde a aparência efetivamente mostra a vida diária. $\mathrm{O}$ autor $^{(4)}$ afirma que todos os aspectos da vida cotidiana, do existir social, encontram-se marcados pelo selo do teatral, e é esta teatralidade, em suas diferentes modulações e contradições, que permite a perduração do social.

Teatralizando, as coisas e as pessoas se apresentam como realmente são, com seus diversos e movediços aspectos, revelando suas múltiplas facetas, as quais podem se articular e acomodar-se entre si.

Neste contexto, sinais de um estar-junto conflitivo podem se declarar no teatral do viver cotidiano, que se apresenta com elementos complementares:

[...] ela falou que pra ela (mãe e dependente) não era fácil. Eu falei pra ela: 'você acha que é fácil, não vamos colocar em questão o fato de no momento você estar dependente, de você estar numa cadeira de rodas: a gente não se cansa disso, mas a gente se cansa do jeito que você trata a gente às vezes', [...] (Branca/Gf II).

Este exemplo retrata que as pequenas atitudes negativas que se reproduzem no dia-a-dia do viver podem permanecer latentes, e a sua repetição reforça a produção de elementos que vão interferir nas relações dos membros familiares.

As relações se sustentam ainda por aspectos que não são aceitos interiormente, mas, por serem intrínsecos ao viver, participam do que caracteriza o teatral e integram a perduração do social:

[...] É só eu (filha) que dou o banho; e aí se eu não estou em casa? Todo mundo tem mão e sou só eu que ela (mãe e dependente) quer para o banho. Não gosto de pegar na perna dela porque ela só reclama, para mim está um horror ver e pegar na perna dela. À noite eu vejo a perna, escuto grito, à noite, às vezes, eu não durmo, e ela quer que só eu pegue na perna dela [...] (Violeta (EI)/F. Flores).

A presença da doença estabelece uma situação imposta à família, a obrigatoriedade em assumir o papel de cuidador ${ }^{(7)}$. Neste sentido, evidenciamos no relato que, pelo rito no cuidado, as imagens vão se formando de maneira a repercutirem no viver e no sentir. É possível perceber que muitas atitudes, quando executadas por obrigação, podem exteriorizar a negação por caminhos subjetivos, como um teatral, e é esta expressão que permite a manutenção do equilíbrio nas relações da família.

Pensando no teatral como parte do cotidiano, observamos que a teatralização que se exibe nos relatos ainda apresenta a harmonia conflitual, a qual permite a estruturação social com a presença do heterogêneo, revelando os valores culturais que são considerados pelos membros do grupo:

[...] Eu (filho) ainda não acredito de certa forma, que tudo o que aconteceu (doença) [...] a minha vida até certo ponto parece que era escrita de uma forma, parece que pegou aquele livro e jogou do outro lado, e começou outra coisa, sabe. Parece que eu nasci, minha vida mudou completamente depois disso, porque de certa forma o pai e a mãe são heróis pra você, sabe, são espelhos, são de certa forma refúgios pra você.[...] mesmo que eu não demonstrasse um desespero muito grande, eu guardei muito para mim certas coisas, mas é, o que eu posso dizer..., depois eu chorei [...] (Arara/Gf I).

Revela-se de maneira transparente a preocupação do filho em respeitar o papel de pai, valorizando o que social e culturalmente é transmitido, que os pais são os melhores, que eles são o exemplo de vida, etc. Mesmo que esta "imagem" até o momento não tenha sido positiva, agora, com a doença, surge uma nova oportunidade de o pai realmente se mostrar como o maior e melhor, afirmando o valor culturalmente recebido.

Seguindo-se na análise da teatralização, as falas revelam que a necessidade de cuidado físico impõe uma dinâmica de relações que altera valores e atitudes familiares, impondo-Ihes uma revisão:

[...] Eu (mãe e dependente) precisei ficar sem roupa para ir no banheiro tomar um banho, [...] eu tive que trabalhar com essa inibição, de 'ai, meu filho vai ver eu sem roupa', só que ele me via sem malícia, [...] na primeira semana foi desagradável, só que eu encarei melhor quando eu vi que ele não ficava envergonhado [...] ele ficava me tirando essa inibição, essa vergonha. Ele mesmo me transmitiu essa segurança, porque eu ia ficar sem roupa perto dele, mas ele não estranhou e não achava feio. Ele encarou como uma necessidade natural, normal, de 
estar me vendo como uma pessoa que estava precisando de uma ajuda [...] (Amarela (EI)/Dep. F. Cores).

Ficar desnudo diante de outra pessoa, como mãe e filho, é mexer com o não-convencional. Culturalmente é passada de geração em geração a importância do recato com o corpo, da valorização do pudico.

Quando uma pessoa necessita romper com estes valores, primeiramente ela tem que enfrentar-se a si mesma. Com a presença da doença e dependência a pessoa não tem escolha, ela é obrigada a vencer seus próprios limites e abrir caminho, porque o novo está diante dela.

Para uma pessoa, mesmo doente, ficar despida pode apresentar-se com o sentido de desconforto e embaraço, pois culturalmente nos é passado que expor o corpo não é apropriado. Geralmente a nudez é relacionada com a sensualidade e sexualidade e vista até de forma vulgar, sendo reprimida de acordo com os padrões de comportamento que se apresentam em um determinado tempo-espaço ${ }^{(19)}$.

A presença inesperada da doença não toca apenas nos valores; ela perturba diversos aspectos da vida, interferindo nas rotinas e nos hábitos corriqueiros do dia-a-dia; ou seja, as práticas constantemente trilhadas e sabidas dos membros familiares sofrem alterações pela presença do dependente:

[...] Depois do AVC do meu pai muitas coisas mudaram em nossas vidas nesse período. Eu (filho Carinho) [...] tive que conciliar o meu trabalho com os cuidados com o meu pai. Pois saio de manhã às 8 horas e na hora do almoço ajudo minha cunhada a dar banho nele, à tarde trocá-lo. Na parte da tarde volto no meu horário de trabalho somente para tirálo da cama para sentá-lo. [...] Todo aquele tempo disponível que nós tínhamos para cuidar de determinados assuntos e atividades depois do trabalho foram preenchidos com a atenção e os cuidados para o meu pai [...] (Carinho (EI)/F. Afeto).

Temos também o relato que identifica, além das mudanças de atividades e de tempo, as alterações que se fizeram necessárias na parte física da casa:

[...] Tivemos que mudar primeiro, quarto, muitas coisas teve que tirar da frente porque ia atrapalhar, ia cair, a gente teve que mudar o horário de comida [...]. Nos primeiros dias pra mim (esposa) foi muito difícil [...] (Mãe Arara/Gf II).

Estudos $^{(7,9,20)}$ declaram as diversas alterações que podem ocorrer com a presença da doença crônica no ambiente familiar. Confirmamos que, além de mudanças na estrutura física, nas rotinas e hábitos familiares, a presença da doença também pode tornar diferentes os caminhos comuns para o lazer e os prazeres sociais de todos os membros que compõem o grupo. Ou seja, coisas habituais e simples, como uma visita, tornam-se difíceis de realizar.

Todos os elementos se revestem de muito sentido no viver cotidiano, desta forma não podemos considerar as banalidades, os pequenos momentos festivos, as deambulações diárias, os lazeres, etc. como algo sem importância ou frivolidades da vida ${ }^{(5)}$.

O viver cotidiano, com seus ritos, aparece como sendo o teatral em ato aonde cada história vai tomando forma, cor e movimento de acordo com os elementos que se apresentam naquele momento e contexto.

\section{CONSI DERAÇÕES}

É perceptível no estudo, pela análise do trágico e do teatral, que o viver cotidiano se compõe de partes de naturezas distintas; mas é esta diferença que se encontra presente nos ciclos vitais e nos grupos que participa do que é verdadeiro, que cria por meio da repetição, dos rituais, as histórias familiares de vida, as histórias de uma comunidade, de uma nação, ou seja, de todo o existir social.

Compreender o sentido trágico, próprio de existência humana é apreender a manifestação do trágico no instante vivido pelo que é, com o reconhecimento amargo, porém sem se preocupar com as certezas, que vêm a longo prazo; é ver o trágico fundando-se no presente, com sua intensidade e com o que tem de transitório.

O teatral que se declara pelo rito tem, principalmente, o efeito de manifestar no viver cotidiano as harmonias conflitivas, objetivas ou subjetivas, permitindo a estruturação individual e dos grupos, e assim a perduração do social.

Destarte, cremos que este trabalho contribui para a ciência do cuidado despertando, no profissional de saúde, a necessidade de prestar atenção a todas as ações efetuadas pelas pessoas para defrontar as imposições físicas, emocionais e sociais que emergem do trágico e que exibem a teatralidade vivida cotidianamente. Visto que, isso é a declaração de sua vontade de mudança e o enfrentamento das imposições, mostrando o desejo de viver o presente, com suas pequenas mortes, mas principalmente buscando o hedonismo. E, esta compreensão cooperará na prestação de um cuidado humanizado, individualizado a cada membro familiar, em seu tempo-espaço.

\section{REFERÊNCI AS}

1. Petrini J C. Notas para uma antropologia da família [Internet]. São Paulo: ejesus; 2004 [cited 2009 mar 2]. Available from: http: //www. ejesus. com. br/exibe. asp?id=2055.

2. Elsen I, Marcon SS, Santos MR. O viver em família e sua interface com a saúde e a doença. 2nd ed. Maringá: Eduem; 2004.

3. Marques S, Rodrigues RAP, Kusumota L. O idoso após acidente vascular cerebral: alterações no 
relacionamento familiar. Rev Latino-am Enfermagem. 2006; 14(3): 364-71.

4. Maffesoli M. A conquista do presente: para uma sociologia da vida cotidiana. Souza Filho A de, translator. Natal: Argos; 2001.

5. Maffesoli M. No fundo das aparências. 2nd ed. Gurovitz BH, translator. Petrópolis: Vozes; 1996.

6. Maffesoli M. O conhecimento comum: compêndio de sociologia compreensiva. Trinta AR, translator. São Paulo: Brasiliense; 1988.

7. Montezuma CA, Freitas MC, Monteiro ARM. A família e o cuidado ao idoso dependente: estudo de caso. Rev. Eletr. Enf. [Internet]. 2008 [cited 2009 feb 16]; 10(2):395-404. Available from: http://www.fen.ufg.br/revista/v10/n2/v10n2a11.htm 8. Miguel MEGB, Pinto MEB, Marcon SS. A dependência na velhice sob a ótica de cuidadores formais de idosos institucionalizados. Rev. Eletr. Enf. [Internet]. 2007 [cited 2009 feb 16];9(3):784-95. Available from: http://www.fen.ufg.br/revista/v9/n3/v9n3a17. htm.

9. Silveira TM, Caldas CP, Carneiro TF. Cuidando de idosos altamente dependentes na comunidade: um estudo sobre cuidadores familiares principais. Cad. Saúde Pública. 2006;22(8): 1629-38.

10. Pavarini $\mathrm{SCl}$, Melo LC, Silva VM, Orlandi FS, Mendiondo MSZ, Filizola CLA et al. Cuidando de idosos com Alzheimer: a vivência de cuidadores familiares. Rev. Eletr. Enf. [Internet]. 2008 [cited 2009 feb 16];10(3):580-90. Available from: http://www. fen.ufg.br/revista/v10/n3/v10n3a04.htm 11. Bocchi SCM. Vivenciando a sobrecarga ao vir-aser um cuidador familiar de pessoa com acidente vascular cerebral (AVC): análise do conhecimento. Rev Latino-am Enfermagem. 2004; 12(1): 115-21.

12. Maffesoli M. A contemplação do mundo. Settineri FF, translator. Porto Alegre: Artes e Ofícios; 1995.

13. Castilho T. Painel: Família e relacionamento de gerações. In: Congresso Internacional Co-Educação de Gerações [Internet]; 2003; São Paulo, Brasil. 2003 [cited 2009 feb 16]. Available from: http://www.sescsp.org.br/sesc/images/upload/confer encias/94.rtf.

14. Maffesoli M. Dinâmica da violência. França CMV, translator. São Paulo: Revista dos Tribunais; 1987.

15. Maffesoli M. A parte do diabo: resumo da subversão pós-moderna. Marques C, translator. Rio de J aneiro: Record; 2004.

16. Maffesoli M. O instante eterno: o retorno do trágico nas sociedades pós-modernas. Dias $A$, Almeida R de, translator. São Paulo: Zouk; 2003.

17. Maffesoli M. A transfiguração do político: a tribalização do mundo. Silva JM, translator. Porto Alegre: Sulina; 1997.

18. Cerveny CMO, Berthoud CME. Visitando a família ao longo do ciclo vital. São Paulo: Casa do Psicólogo; 2002.

19. Pupulim JSL, Sawada NO. O cuidado de enfermagem e a invasão da privacidade do doente: uma questão ético-moral. Rev Latino-am Enfermagem. 2002; 10(3): 433-38.

20. Santos SSC, Pelzer MT, Rodrigues MCT. Condições de enfrentamento dos familiares cuidadores de idosos portadores de doença de Alzheimer. Revista Brasileira de Ciências do Envelhecimento Humano - Passo Fundo. 2007; 4(2): 114-26.

Artigo recebido em 11.02.08.

Aprovado para publicação em 31.03.09. 